\title{
OPTIMIZACIJA ISKORIŠĆENJA TOVARNOG PROSTORA FORMIRANJEM GEOMETRIJSKOG MODELA PLANA PAKOVANJA POŠILJAKA
}

\author{
Dragan Lazarević, \\ Momčilo Dobrodolac, \\ Maja Petrović \\ Saobraćajni fakultet, \\ Univerzitet u Beogradu, \\ Beograd, Srbija
}

Odgovorno lice:

Dragan Lazarević

e-pošta:

d.lazarevic@sf.bg.ac.rs

\section{Rezime:}

U radu se predlaže koncept za unapređenje nivoa efikasnosti iskorišćenja tovarnog prostora transportnih sredstava u okviru sistema za distribuciju robe i pošiljaka. Ovaj koncept se zasniva na rešavanju problema trodimenzionalnog pakovanja (3D Bin Packing Problem). Predstavljen je primer iz realnog sistema poštanske kompanije u Srbiji, kao jednog od najvećih logističkih i distributivnih sistema u regionu. Definisani problem, dobija dodatno na važnosti usled pojave velikog broja nestandardnih pošiljaka (paketa) u sistemima za njihovu preradu i transport. Značajan uticaj na povećanje broja pošiljaka ima ekspanzija e-trgovine. Rešenje ovog problema je predstavljeno geometrijskim modelom plana pakovanja robe i pošiljaka, a u skladu sa njihovim karakteristikama i kapacitetom tovarnog prostora transportnog sredstva.

Ključne reči:

Trodimenzionalno pakovanje, pošiljke, tovarni prostor, transportno sredstvo, geometrijski model.

\section{UVOD}

U savremenom čovekovom okruženju, prisutni su različiti sistemi, koji svakom pojedincu, kroz uslužne delatnosti, pružaju mogućnost da realizuje svoje poslovne i privatne potrebe. Uslužna delatnost, posmatrajući od poslednje decenije prethodnog veka, jeste jedan od sektora sa izraženo visokim stepenom razvoja. Ako posmatramo razvijene zemlje, u uslužnom sektoru radi preko $70 \%$ od ukupnog broja zaposlenih [1]. Proizvodnja bez plasmana nema značajnu svrsishodnost i zato je neophodno istaći važnost transporta proizvoda. Transportne aktivnosti se realizuju kroz odgovarajuće sisteme distribucije, koji mogu biti različitog obima i nivoa složenosti. U slučaju distribucije robe široke potrošnje, sistemi distribucije nude pojedinačnu ili kompletnu uslugu, koja može obuhvatati uvoz i carinjenje robe, skladištenje, marketinške usluge, prodaju i dostavu. U skladu sa savremenim tendencijama održivog razvoja, prisutna je globalna svest i težnja za unapređenjem ekonomske, društvene i ekološke dimenzije svakog poslovnog sistema [2], što zahteva sprovođenje kontinualnih analiza i odgovarajućih aktivnosti unapređenja. 
U okviru ovog rada, analiziran je proces transporta ekspres pošiljaka u poštanskoj kompaniji, koja predstavlja jedan od najvećih logističkih i distributivnih sistema u Srbiji i regionu. Identifikovani su određeni problemi i izazovi, koji su nastali pre svega pojavom velikog broja nestandardnih pošiljaka u sistemu. Jedan od osnovnih razloga ovog trenda jeste ekspanzija lanaca e-trgovine i učešće poštanskih kompanija $\mathrm{u}$ istim, pre svega u segmentu dostave kupljene robe. Jedan od izdvojenih problema, odnosi se na efikasnost iskorišćenja tovarnog prostora transportnih sredstava usled nemogućnosti potpuno kompaktnog pakovanja nestandardnih pošiljaka. Konsekvence inicirane ovim problemom, odnose se pre svega na pojavu slučaja da se sve pošiljke na stanju, za posmatranu liniju prevoza, ne mogu spakovati u predviđeni tovarni prostor. To može dovesti do kašnjenja pri prenosu pošiljaka (čekanje na narednu liniju po redu prevoza), odnosno do potrebe za angažovanjem dodatnih resursa (transportno sredstvo i kurir) čime se uvećavaju troškovi. Sve ovo doprinosi formiranju negativnog uticaja na održivi razvoj poštanske usluge.

U cilju optimizacije iskorišćenja tovarnog prostora pri prenosu pošiljaka, predlaže se uvođenje i primena koncepta rešavanja problema pakovanja (3D Bin Packing Problem), na osnovu koga se formira geometrijski model plana pakovanja u skladu sa odgovarajućim ograničenjima. Prikazani su rezultati primene koncepta na primeru iz realnog sistema, pri čemu je za rešavanje zadatka trodimenzionalnog pakovanja, korišćen specijalizovani softver EasyCargo.

\section{KONCEPT PROBLEMA PAKOVANJA}

Problem pakovanja se u literaturi najčešće sreće kao $3 D$ Bin Packing Problem, odnosno kao problem trodimenzionalnog pakovanja. Međutim, ovom konceptu su prethodili pristupi za rešavanje problema u jednoj odnosno dve dimenzije.

\section{Jednodimenzionalni i dvodimenzionalni problemi pakovanja}

Jednodimenzionalno pakovanje podrazumeva zadatak, gde je određenu robu, predmete ili pakete potrebno smestiti u odgovarajuće tovarne (teretne) prostore, tako da njihovo iskorišćenje bude na visokom nivou, pri čemu se vodi računa o samo jednom ograničenju - dimenziji (npr. nosivost transportnog sredstva) [3].
Dvodimenzionalni problem pakovanja (2D Bin Packing Problem) jeste unapređenje jednodimenzionalnog problema u pogledu ograničenja, koja se pri pakovanju uzimaju u obzir. Naime, kod ovog zadatka, posmatraju se dva ograničenja - dimenzije (npr. dužina i širina paketa). Jedan od prvih zadataka iz ove oblasti, koji se može pronaći u literaturi, jeste pakovanje (postavljanje) što većeg broja manjih pravougaonika određenih dimenzija (bez preklapanja), na površinu jednog većeg pravougaonika [4].

\section{Trodimenzionalni problem pakovanja - 3D Bin \\ Packing Problem}

Za trodimenzionalni zadatak pakovanja, se može reći da predstavlja specijalan slučaj, odnosno sintezu prethodno definisanih problema, u kome se u obzir uzimaju bar tri ograničenja - dimenzije [5]. Rešenje ovog zadatka podrazumeva formiranje geometrijskog modela plana pakovanja u okviru definisanog tovarnog prostora, kontejnera, na paleti i sl.

Opšti matematički model podrazumeva zadatak pakovanja paketa određenih dimenzija u tovarni prostor definisane strukture i kapaciteta, pri čemu je osnovni cilj njegovo maksimalno iskorišćenje, odnosno kompaktno pakovanje i smanjenje prostora između paketa [6].

$3 D$ Bin Packing Problem se često povezuje sa utovarom robe i paleta u tovarni prostor transportnog sredstva ili u kontejner, ali i na brojne druge modifikacije, kao što je pakovanje robe na palete. Među prvim radovima u ovoj oblasti je rešenje koje je predstavio Wright 1974. godine, a odnosilo se na formiranje najpogodnije konfiguracije za utovar paleta u tovarni prostor [7]. Zadatku $3 D$ pakovanja, mogu se dodati različita ograničenja i specifičnosti, poput rotacije paketa (da/ne), definisanja njihovog prioriteta pri pakovanju, analize stabilnosti i sl. $[8,9,10]$. 3D Bin Packing Problem je delimično, kao koncept, analiziran od strane Lin-a i saradnika (2016) u oblasti dostave paketskih pošiljaka. U okviru pomenute studije, cilj je bio primeniti koncept $3 D$ pakovanja i pri tome eliminisati dodatni pretovar paketa nakon svake izvršene dostave [11].

Do danas je razvijen značajan broj algoritama za rešavanje zadataka $2 D$ i $3 D$ pakovanja $[12,13,14,15$, $16,17]$. Neki od njih su primenu našli i u odgovarajućim specijalizovanim softverima. 


\section{PREDLOG KONCEPTA ZA REŠAVANJE 3D BIN PACKING PROBLEM-A PRI PRENOSU EKSPRES POŠILJAKA}

Značaj rešavanja problema trodimenzionalnog pakovanja pri prenosu ekspres pošiljaka, polazi od činjenice da se u sistemima za prenos pojavljuje sve veći broj pošiljaka nestandardnih dimenzija. Izvor ovih pošiljaka su pre svega lanci e-trgovine. Naime, kako bi unapredile svoju poziciju na tržištu i pridobile veći broj korisnika, a sve u cilju uvećanja profita, poštanske kompanije su prinuđene da uzmu učešće u lancima e-trgovine, a samim tim i da prihvataju na prenos sve veći broj nestandardnih pošiljaka. Nestandardne pošiljke su sve one pošiljke koje svojim dimenzijama i ostalim karakteristikama ne odgovaraju propisanim standardima. Automatizovani sistemi u poštanskim kompanijama su prilagođeni za rad sa standardnim pošiljkama, što dalje implicira na nemogućnost automatizovane prerade nestandardnih pošiljaka. Iz tog razloga se ove pošiljke uglavnom prerađuju manuelno.

Značajni problemi se javljaju prilikom pakovanja nestandardnih pošiljaka u tovarni prostor transportnog sredstva. Ove pošiljke se ne mogu upakovati u standardnu ambalažu za prenos ekspres pošiljaka, tako da se u transpotno sredstvo pakuju u sopstvenoj ambalaži (ako je poseduju). Navedeno utiče na nemogućnost potpuno kompaktnog pakovanja i na smanjenje nivoa iskorišćenja tovarnog prostora, što indirektno može izazvati brojne probleme. Dešava se da usled nedostatka mesta u tovarnom prostoru nije moguće utovariti sve pošiljke, predviđene definisanim redom prevoza, a u skladu sa vremenskim rokovima uručenja. U navedenom slučaju su moguća dva scenarija: transport pošiljaka linijama sa kasnijim polascima (može izazvati kašnjenje pošiljaka na uručenje); angažovanje dodatnih resursa (transportno sredstvo i kurir) kako bi se transport preostalih pošiljaka realizovao po unapred definisanom redu prevoza. Kod drugog scenarija, pojavljuju se dodatni troškovi, koji se ne mogu nadoknaditi kroz cenu usluge, dok je usled angažovanja dodatnog transportnog sredstva evidentan i negativan uticaj na životnu sredinu.

Nestandardne pošiljke su podložne oštećenju, kako pri pretovarnim manipulacijama, tako i u okviru procesa transporta. Naime, nemogućnost kompaktnog pakovanja ostavlja veći prostor između pošiljaka, što uvećava verovatnoću da tokom transporta dođe do njihovog pomeranja, klizanja i nagnječenja. Kako je naglašeno, u sistemima poštanskih kompanija, pojavljuje se sve veći broj različitih pošiljaka, odnosno robe različitih karakteristika, osetljivosti i vrednosti, što dodatno doprinosi značaju navedenog problema.
Rastući trend e-trgovine će i u budućnosti uticati na pojavu sve većeg broja nestandardnih pošiljaka u sistemima poštanskih kompanija. U skladu sa tim i navedenim problemima, potrebno je na odgovarajuće načine unaprediti njihove poslovne procese, kako bi se eliminisale negativne posledice. Analiza izdvojenog problema pakovanja pošiljaka, ukazala je na potrebu primene odgovarajućeg pristupa, koji bi omogućio njihovo kompaktno pakovanje, odnosno unapredio efikasnost iskorišćenja tovarnog prostora.

Predlaže se primena koncepta rešavanja $3 D$ bin packing problem-a. Podrazumeva kreiranje geometrijskog modela, odnosno plana na osnovu koga treba realizovati pakovanje, a u zavisnosti od definisanih karakteristika tovarnog prostora i pošiljaka. Benefiti primene ovog pristupa proističu iz samog unapređenja efikasnosti iskorišćenja tovarnog prostora, a odnose se pre svega na eliminisanje vremenskih kašnjenja, unapređenje bezbednosti pošiljaka i smanjenje broja potrebnih transportnih sredstava (smanjenje troškova i negativnog uticaja na životnu sredinu).

\section{Predlog realizacije koncepta 3D bin packing problem-a}

Realizacija koncepta rešavanja $3 D$ bin packing problem-a u okviru sistema za prenos ekspres pošiljaka se može prikazati narednim koracima:

- 1. korak: Prikupljanje informacija o fizičkim karakteristikama pošiljaka (dužina, širina, visina i masa);

- 2. korak: Definisanje tovarnog prostora, odnosno transportnog sredstva;

- 3. korak: Primena softvera za rešavanje $3 D$ bin packing problem-a;

- 4. korak: Analiza dobijenog rešenja;

- 5. korak: Pakovanje pošiljaka u skladu sa definisanim geometrijskim modelom plana pakovanja.

U prvom koraku se u skladu sa odgovarajućim pristupom za svaku pošiljku određuju osnovne karakteristike: dužina, širina, visina i masa. Standardan pristup za određivanje ovih karakteristika, podrazumeva manuelno merenje, koje bi u skladu sa brojem pošiljaka oduzelo značajno vreme, pa bi i sam koncept bio neracionalan za primenu. Masa pošiljaka se i u dosadašnjem načinu prenosa uzimala u obzir, a primena preciznih elektronskih vaga doprinosi da se ova karakteristika može efikasno i jednostavno odrediti.

Kada je reč o određivanju ostalih potrebnih karakteristika (dužina, širina i visina), mogu se koristiti 
savremeni pristupi, koji su nastali kao rezultat razvoja novih tehnologija. Na prvom mestu, predlaže se upotreba $3 D$ skenera ili kombinovana primena odgovarajućih senzora i koncepta Internet of Things (IoT).

$\mathrm{U}$ drugom koraku se definiše tovarni prostor predviđenog transportnog sredstva, u zavisnosti od nivoa u sistemu na kome se transport realizuje. Treći korak u rešavanju ovog problema (3D bin packing problem) obuhvata primenu odgovarajućeg softvera, u skladu sa ulaznim podacima koji su rezultat prva dva koraka. Izlaz iz softvera, odnosno rešenje, predstavljeno je geometrijskim modelom plana najpogodijeg načina pakovanja u skladu sa zadatim ograničenjima. U četvrtom koraku se dobijeno rešenje dodatno analizira i eventualno uvode određene korekcije. Peti korak podrazumeva fizičku realizaciju pakovanja na osnovu definisanog geometrijskog modela plana pakovanja.

U nastavku će biti prikazano rešavanje problema pakovanja ekspres pošiljaka, na primeru iz jednog realnog sistema poštanske kompanije u Srbiji.

\section{REŠAVANJE 3D BIN PACKING PROBLEM-A NA PRIMERU IZ REALNOG SISTEMA ZA PRENOS EKSPRES POŠILJAKA}

Analizirani zadatak pakovanja se odnosio na primer iz realnog sistema poštanske kompanije. Pošiljke, prikupljene sa određenih rejona, trebalo je transportovati u preradni centar. Pri utovaru u transportno sredstvo, određeni broj pošiljaka (oko 15\% od ukupne količine) nije mogao da stane u predviđeni tovarni prostor. Kako je već naglašeno, u ovoj situacije se čeka naredni polazak na istoj liniji prevoza, odnosno angažuju se dodatni resursi, kako bi se transport odmah realizovao, što dovodi do opisanih negativnih posledica. Primenom predloženog koncepta, moguće je: kreirati geometrijski model plana pakovanja, na osnovu koga će sve pošiljke biti spakovane; ukazati na nemogućnost utovara svih pošiljaka u definisani tovarni prostor. Rezultati koji se odnose na drugi slučaj, mogu poslužiti kao inicijator promena u organizaciji transporta (angažovanje transportnog sredstva sa većim kapacitetom tovarnog prostora, raspodela pošiljaka na dva ili više transportnih sredstava). Rešavanje zadatka je realizovano u skladu sa predloženim koracima, a kao softverska podrška korišćen je EasyCargo softver.

Prvi korak podrazumeva prikupljanje informacija o fizičkim karakteristikama pošiljaka. Kako koncept nije implementiran u posmatranoj kompaniji (ne postoji sistem za prikupljanje svih neophodnih informacija), za posmatrani slučaj nije bilo moguće potpuno precizno odrediti potrebne karakteristike, jer se o njima u standardnom poslovnom procesu ne vodi takva evidencija. $\mathrm{U}$ Tabeli 1, prikazani su zahtevi, odnosno broj i karakteristike pošiljaka koje je trebalo upakovati u tovarni prostor određenog transportnog sredstva. Precizne informacije o karakteristikama su uzete u obzir kod standardnih pošiljaka (dimenzije ambalaže), dok su karakteristike preostalih - nestandardnih pošiljaka definisane u saradnji sa zaposlenima u kompaniji, koji su u posmatranom slučaju, radili na poslovima pretovara i usmeravanja pošiljaka. Dužina punih vreća je iznosila oko $100 \mathrm{~cm}$, dok je prečnik iznosio približno $70 \mathrm{~cm}$. Tačne informacije o masi pošiljaka, nisu bile dostupne, ali je ukupna masa po proceni zaposlenih bila u granicama nosivosti predviđenog transportnog sredstva. Iz tog razloga, pošiljkama su dodeljene proizvoljne vrednosti mase.

$\mathrm{Na}$ Slici 1, prikazan je segment za kreiranje pošiljaka (paketa) u softveru EasyCargo. Jedna od mogućnosti koju većina softvera iz ove oblasti poseduje, jeste povezivanje sa odgovarajućim tabelama iz softvera Excel, što u velikoj meri može doprineti efikasnosti primene koncepta. Ova opcija je naročito od značaja ukoliko se informacije o karakteristikama dobijenim sa $3 D$ skenera $\mathrm{i}$ precizne vage, po automatizmu skladište u odgovarajuću Excel tabelu.

Tabela 1. Karakteristike zahteva

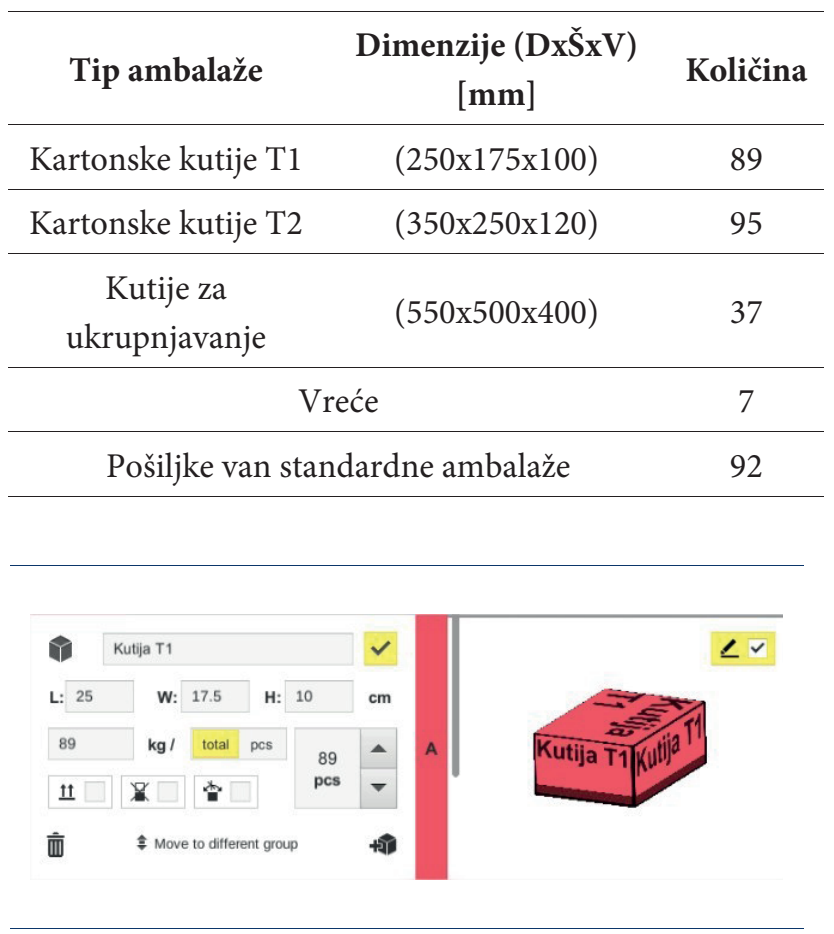

Slika 1. Kreiranje pošiljke (paketa) u softveru EasyCargo 
U drugom koraku se definiše tovarni prostor u koji treba spakovati pošiljke. U analiziranom slučaju, korišćeno je vozilo FIAT Ducato, nosivosti $1440 \mathrm{~kg}$, sa sledećim dimenzijama tovarnog prostora: dužina 4070mm; širina - 1870mm; visina - 1932mm. Na Slici 2, prikazan je modul za definisanje tovarnog prostora.

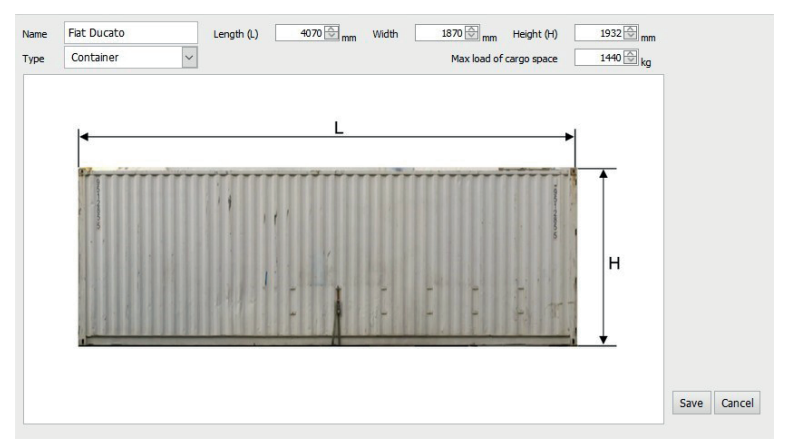

Slika 2. Definisanje tovarnog prostora

U trećem koraku se primenom softvera rešava $3 D$ Bin Packing Problem, odnosno kreira geometrijski model plana pakovanja. U konkretnom slučaju, dobijeno je rešenje po kome je sve pošiljke na stanju moguće upakovati u definisani tovarni prostor, za razliku od realnosti gde je van tovarnog prostora ostalo oko $15 \%$ od ukupne količine pošiljaka. Iskorišćenje tovarnog prostora rešenja, prikazano kroz procenat zauzetosti iznosi oko 79\%. Pošiljke sa naznakom za posebno rukovanje, pre svega lomljive, koje se nalaze van ambalaže za ukrupnjavanje, su od strane korisnika softvera smeštene u plan pakovanja, kako bi se povećao nivo njihove bezbednosti. Na slikama (Slika 3 - Slika 5) dat je geometrijski prikaz modela plana pakovanja u različitim pogledima, kao grafički izlaz softvera.

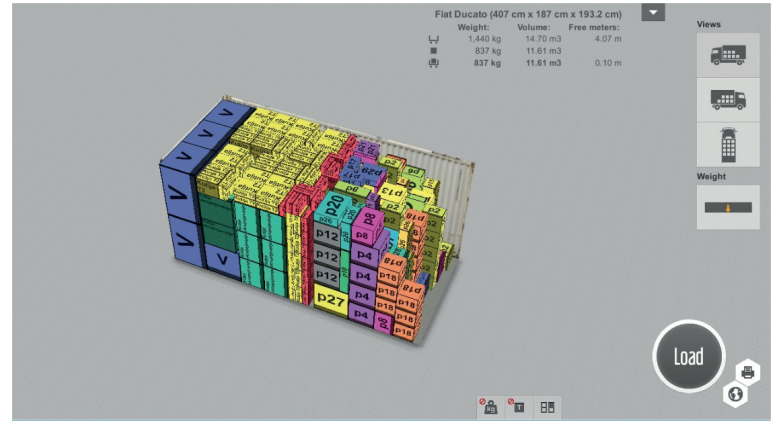

Slika 3. Geometrijski model plana pakovanja (perspektivni prikaz 1)

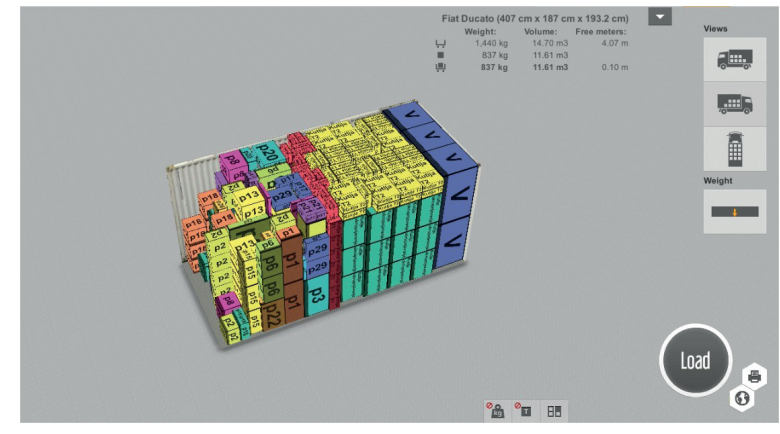

Slika 4. Geometrijski model plana pakovanja (perspektivni prikaz 2)

Rešenje dobijeno ovim putem se može razložiti, kako bi se izdvojio detaljniji vizuelni plan. Nivo razlaganja zavisi od strukture pošiljaka, odnosno od nivoa preglednosti pozicije pošiljaka u tovarnom prostoru.

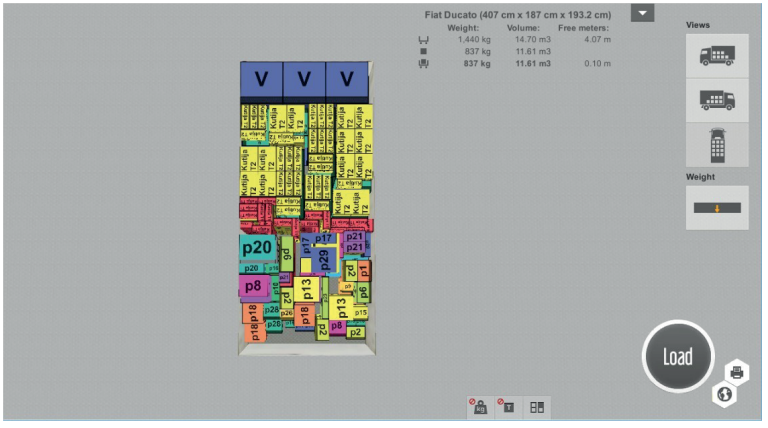

Slika 5. Geometrijski model plana pakovanja (perspektivni prikaz 3)

Na narednim slikama (Slika 6 - Slika 9) je prikazan plan pakovanja sa proizvoljnim nivoom razlaganja.

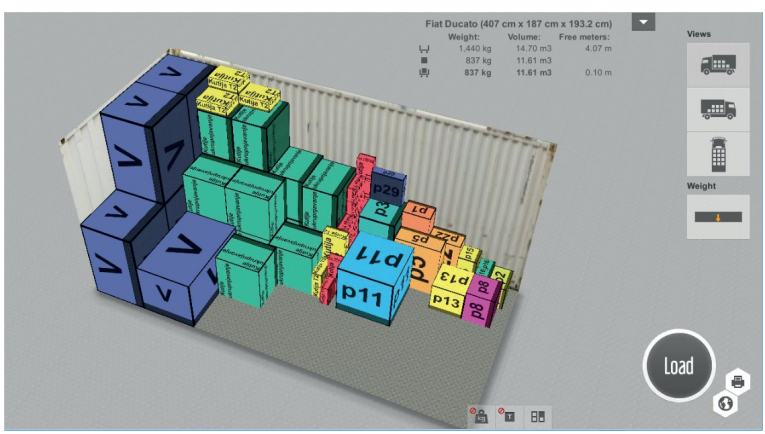

Slika 6. Razloženi geometrijski model plana pakovanja - nivo 1 


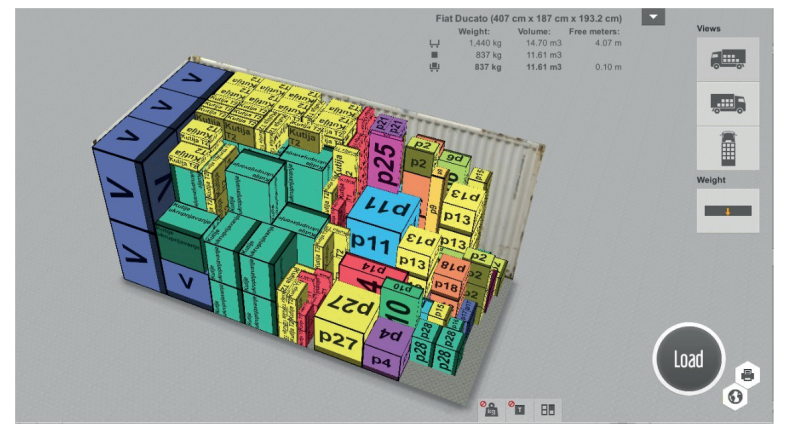

Slika 7. Razloženi geometrijski model plana pakovanja - nivo 2

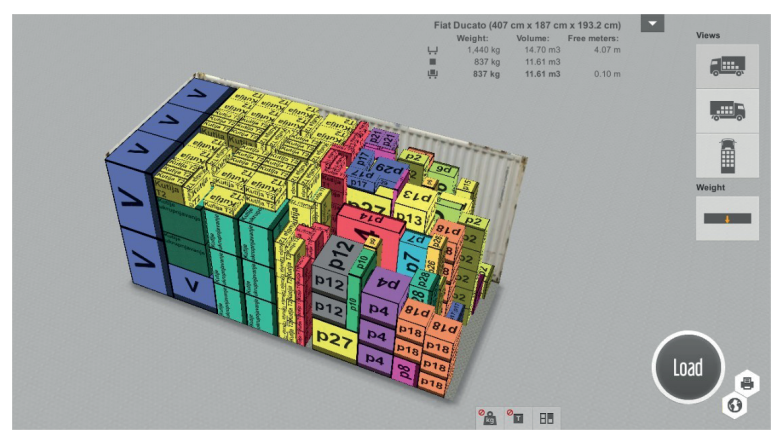

Slika 8. Razloženi geometrijski model plana pakovanja - nivo 3

Broj nivoa razlaganja zavisi od strukture geometrijskog modela plana pakovanja. Teoretski, nivoa može biti onoliko koliko ima pošiljaka za pakovanje (utovar). Poslednji nivo, predstavlja potpuni plan pakovanja, koji je prikazan u radu kao dobijeno konačno rešenje.

Analiza rešenja podrazumeva proveru da li se sve pošiljke nalaze u planu pakovanja, kao i pozicije pošiljaka sa posebno naznačenim rukovanjem i osetljivim sadržajem. Softver pruža mogućnost manuelne korekcije pozicije pošiljaka, ukoliko se za to ukaže potreba, kao i generisanje izveštaja o njihovom statusu. $\mathrm{Na}$ osnovu rešenja i kreiranog geometrijskog modela plana pakovanja, analizira se kojim transportnim sredstvom je najpogodnije realizovati transport. U slučaju niskog nivoa iskorišćenja tovarnog prostora, potrebno je razmatrati korišćenje transportnog sredstva sa manjim kapacitetom. U suprotnom slučaju, kada je kapacitet tovarnog prostora nedovoljan za utovar svih pošiljaka, rešava se zadatak izbora koncepta transporta - jedno veće transportno sredstvo ili 2 ili više manjih. Izbor drugog koncepta, podrazumeva rešavanje dodatnog zadatka, koji se odnosi na raspodelu pošiljaka između transportnih sredstava. U konkretnom primeru nije bilo značajnih korekcija, a one koje su izvršene, deo su prikazanog konačnog rešenja geometrijskog modela plana pakovanja.

\section{ZAKLJUČAK}

U sistemima distribucije različitih pošiljaka i robe, kao što su poštanske kompanije, izražen je porast broja nestandardnih pošiljaka. Razlog tome jeste, pre svega, njihovo učešće u lancima e-trgovine u segmentu dostave kupljene robe.

Nestandardne pošiljke izazivaju različite konsekvence u procesu prerade i transporta, koje negativno utiču na efikasnost realizacije čitavog poslovnog procesa prenosa. Analizom aktivnosti koje prethode procesu transporta, zaključeno je da nivo iskorišćenja tovarnog prostora transportnih sredstava, ima značajan uticaj na definisani pokazatelj efikasnosti. Kako broj nestandardnih pošiljaka u sistemu raste, smanjuje se mogućnost kompaktnog pakovanja pošiljaka, koje bi obezbedilo visok nivo iskorišćenja tovarnog prostora, a istovremeno imalo i pozitivan uticaj na bezbednost pošiljaka (kompaktno pakovanje umanjuje verovatnoću oštećenja pošiljaka).

U radu se predlaže primena koncepta rešavanja $3 D$ bin packing problem-a. Podrazumeva formiranje geometrijskog modela plana pakovanja pošiljaka, a u skladu sa njihovim karakteristikama i definisanim tovarnim prostorom transportnog sredstva. Kroz primenu koncepta, može se generisati rešenje za kompaktno pakovanje pošiljaka sa visokim nivoom iskorišćenja tovarnog prostora ili ukazati na nedovoljan kapacitet tovarnog prostora anliziranog transportnog sredstva. $U$ radu su prikazani rezultati uspešne primene koncepta na primeru iz realnog sistema poštanske kompanije, pri čemu je korišćen specijalizovani softver EasyCargo.

Ekspanzija e-trgovine će u budućnosti usloviti pojavu još većeg broja nestandardnih pošiljaka, što značajno naglašava važnost rešavanja ove vrste problema.

\section{ZAHVALNOST}

Ovaj rad je podržan od strane Ministarstva prosvete, nauke i tehnološkog razvoja Republike Srbije kroz projekat TR36022. 


\section{LITERATURA}

[1] M. Dobrodolac and D. Lazarević, "Predlog metodologije za definisanje relevantnih parametara kvaliteta poštanske usluge," Zbornik radova „XXXVI Simpozijum o novim tehnologijama u poštanskom i telekomunikacionom saobraćaju PosTel 2018“, Saobraćajni fakultet Univerziteta u Beogradu, Beograd, Srbija, 2018, pp. 109-118.

[2] S. Pejčić-Tarle and N. Bojković, Evropska politika održivog razvoja transporta, Saobraćajni fakultet Univerziteta u Beogradu, 2012.

[3] D. S. Johnson, A. Demers, J. D. Ullman, M. R. Garey and R. L. Graham, "Worst-case performance bounds for simple one-dimensional packing algorithms," SIAM Journal on computing, vol. 3(4), pp. 299-325, 1974.

[4] P. Erdös and R. L. Graham, "On packing squares with equal squares," Journal of Combinatorial Theory, Series A, vol. 19(1), pp. 119-123, 1975.

[5] S. Martello, D. Pisinger and D. Vigo, "The threedimensional bin packing problem," Operations research, vol. 48(2), pp. 256-267, 2000.

[6] C. S. Chen, S. M. Lee and Q. S. Shen, "An analytical model for the container loading problem," European Journal of Operational Research, vol. 80(1), pp. 68-76, 1995.

[7] P. Wright, "Pallet loading configurations for optimal storage and shipping," Paperboard and Packing, pp. 46-49, 1974.

[8] F. K. Miyazawa and Y. Wakabayashi, "Three-dimensional packings with rotations," Computers \& Operations Research, vol. 36(10), pp. 2801-2815, 2009.

[9] L. Junqueira, R. Morabito and D.S. Yamashita, "Three-dimensional container loading models with cargo stability and load bearing constraints," Computers \& Operations Research, vol. 39(1), pp. 74-85, 2012.
[10] A. Lim, H. Ma, J. Xu and X. Zhang, "An iterated construction approach with dynamic prioritization for solving the container loading problems," Expert Systems with Applications, vol. 39(4), pp. 42924305, 2012.

[11] C. C. Lin, J. R. Kang, W. Y Liu and C. C. Li, "On two-door three-dimensional container packing problem under home delivery service," Journal of Industrial and Production Engineering, vol. 33(3), pp. 205-214, 2016.

[12] D. Pisinger, "Heuristics for the container loading problem," European journal of operational research, vol. 141(2), pp. 382-392, 2002.

[13] J. Egeblad and D. Pisinger, "Heuristic approaches for the two-and three-dimensional knapsack packing problem," Computers \& Operations Research, vol. 36(4), pp. 1026-1049, 2009.

[14] X. Feng, I. Moon and J. Shin, "Hybrid genetic algorithms for the three-dimensional multiple container packing problem," Flexible Services and Manufacturing Journal, vol. 27(2-3), pp. 451-477, 2015.

[15] L. Junqueira and R. Morabito, "Heuristic algorithms for a three-dimensional loading capacitated vehicle routing problem in a carrier," Computers \& Industrial Engineering, vol. 88, pp. 110-130, 2015.

[16] C. Paquay, M. Schyns and S. Limbourg, "A mixed integer programming formulation for the three-dimensional bin packing problem deriving from an air cargo application," International Transactions in Operational Research, vol. 23(1-2), pp. 187-213, 2016.

[17] S. Ingala, Approximation Algorithms for Rectangle Packing Problems, Doctoral Dissertation, Faculty of Informatics of the Università della Svizzera Italiana, Lugano, 2017. 